\title{
Incidence and mortality trends of metastatic prostate cancer: Surveillance, Epidemiology, and End Results database analysis
}

\author{
Aaron C. Zhang, BA'; Rehana Rasul, $M A^{2}$; Anne Golden, PhD'; Michael A. Feuerstein, $M D^{3}$ \\ 'Donald and Barbara Zucker School of Medicine at Hofstra/Northwell, Hempstead, NY, United States; ${ }^{2}$ Feinstein Institutes for Medical Research, Department of Occupational Medicine, Epidemiology and \\ Prevention, Zucker School of Medicine at Hofstra/Northwell, Hempstead, NY, United States; ${ }^{3}$ Lenox Hill Hospital, Department of Urology, Zucker School of Medicine at Hofstra/Northwell, Hempstead, NY, \\ United States
}

Cite as: Zhang AC, Rasul R, Golden A, et al. Incidence and mortality trends of metastatic prostate cancer: Surveillance, Epidemiology, and End Results database analysis. Can Urol Assoc J 2021;15(12):E637-43. http://dx.doi.org/10.5489/cuaj.7173

Published online June 22, 2021

\section{Abstract}

Introduction: In the past decade, prostate cancer screening decreased, raising the concern of delays in diagnosis and leading to an increase in new cases of metastatic prostate cancer. This study evaluated whether these changes may have impacted trends in metastatic prostate cancer incidence and survival.

Methods: Metastatic prostate cancer diagnoses from 2008-2016 were identified from the Surveillance, Epidemiology, and End Results (SEER) 18 registries. Age-adjusted incidence rates per 100000 were calculated by time periods and demographic variables. Two-year all-cause and prostate cancer-specific mortality were calculated for patients diagnosed from 2008-2014, and multivariable Cox proportional hazards models were used to evaluate the impact of demographic and clinical variables.

Results: Incidence rates of metastatic prostate cancer increased by $18 \%$ from $2008-2009$ to $2014-2016$ (incidence rate ratio $[I R R]=1.18,95 \%$ confidence interval $[\mathrm{Cl}] 1.14-1.21)$. This trend was observed across multiple subgroups but was greatest in nonHispanic Whites and patients living in counties $0-10 \%$ below poverty level. There was an overall decreased risk of all-cause and prostate cancer-specific mortality, but unmarried men and men living in counties $>20 \%$ below poverty level showed statistically significant increased risk of prostate cancer-specific mortality.

Conclusions: Non-Hispanic Whites and the wealthiest subgroups had the largest increase in incidence of metastatic prostate cancer since 2008. Despite trends of decreased risk of prostate cancer-specific mortality, we found certain populations experienced increases in mortality risk. Studies exploring the role of socioeconomic factors on screening and access to newer treatments are needed.

\section{Introduction}

Prostate cancer is the most common cancer in men in the U.S., with an estimated 191000 new cases diagnosed in $2020 .^{1}$ Despite a five-year relative survival rate of greater than $99 \%$ for localized disease, metastatic prostate cancer (mPCa) remains the second leading cause of cancer-related death in men, with a five-year relative survival rate of $30.2 \% .^{2}$ Prior studies have demonstrated that there has been an increase in the diagnosis of de novo mPCa in the last several years, perhaps related to the U.S. Preventative Services Task Force (USPSTF) recommendation against routine prostate cancer screening for men of all ages in 2012. ${ }^{3-5}$ Considering that race/ethnicity and socioeconomic status have been shown to influence incidence and mortality of cancer, we examined demographic differences in incidence of de novo mPCa and survival from 2008-2016. ${ }^{6,7}$

\section{Methods}

\section{Data sources and study sample}

Data were queried from the Surveillance, Epidemiology, and End Results (SEER) Program's 18 Registries Research Data and Hurricane Katrina Impacted Louisiana cases based on the November 2018 submission using SEER*Stat 8.3.6 software. ${ }^{8}$ SEER is sponsored by the National Cancer Institute to maintain and distribute cancer incidence and survival data from population-based cancer registries representing approximately $28 \%$ of the U.S. population based on the 2010 census. $^{8}$ The SEER registries collect information on the site and extent of disease, first course of cancer-directed therapy, and socio-demographic characteristics, with active followup for date and cause of death. ${ }^{9}$ mPCA counts and population estimates generated from the incidence rate session, stratified by year of diagnosis, age group, race/ethnicity, region, poverty level, and stage, were extracted; health insurance status could not be considered for incidence rate analysis because it is not defined in the U.S. population 
data. Individual data from mPCa cases among males 45 years or older from 2008-2016 were also extracted from the case session. For 2016 cases, SEER classified metastatic stages based on the American Joint Committee on Cancer (AJCC)'s seven staging criteria, with clinical or pathological indication. ${ }^{10}$ Cases with any clinical or pathological indication of metastatic cancer were included. However, mPCa was defined using AJCC 6 staging criteria (M1a, M1b, M1c) for 2008-2015, which did not differentiate between clinical and pathological staging. ${ }^{10}$ Cases with unknown stage or poverty level, or where survival time was zero months after diagnosis, were excluded.

\section{Study variables}

Demographic variables included age group (45-54, 55-64, 65-74, 75-84, 85+ years), race/ethnicity (Non-Hispanic White, Non-Hispanic Black, Non-Hispanic Asian or Pacific Islander, Hispanic [all races]), region (East, Pacific Coast/ Alaska, Northern Plains, Southwest), county measure of percent of persons below the federal poverty level (0-10\%, $>10-15 \%,>15-20 \%,>20 \%$ ), and health insurance (insured, uninsured, unknown). The impact of 2012 screening recommendations was examined using time periods of 20082009, 2010-2011, 2012-2013, and 2014-2016.

\section{Statistical analysis}

Multivariable Poisson regression models for rate analyses were used to calculate mPCA incidence rates and evaluate whether they differed by period, while adjusting for demographic variables and tumor stage. They included an offset using the log (population). Interactions between period and demographic variables or stage were included in separate models to assess whether there were differential trends by these factors. Adjusted incidence rates, presented as the number of mPCa cases per 100000 persons, as well as adjusted incidence rate ratios (IRR) and Bonferroni-corrected 95\% confidence intervals $(\mathrm{Cl})$, were reported. The Bonferroni correction using $\mathrm{p}=0.0019$ (21 subgroup comparisons and five tests for interaction) was applied due to testing multiple comparisons.

Multivariable Cox proportional hazards models were used to determine whether there was a difference in two-year all-cause mortality and prostate cancer mortality between time periods and whether it was modified by demographic variables or stage. Time to the event (all-cause mortality and prostate cancer mortality) was the interval in months between diagnosis and the date of death, loss of followup, or December 2016, whichever was earliest. This analysis was restricted to patients diagnosed between 2008 and 2014 so that all patients had at least two years of followup after diagnosis. The time periods 2008-2009, 2010-2011, and 2012-2014 were compared. Because hazards of treatment variables (chemotherapy, radiation, surgery) and stage were not constant over time, they were not included in the main analyses. As a sensitivity to the results, we performed models stratified by these treatment variables and the observed effects of time period and other adjustment variables were similar (Supplementary Table 1).

$\mathrm{mPCa}$ counts and population estimates were extracted from SEER ${ }^{*}$ Stat software, version 8.3.6 (Surveillance Research Program, National Cancer Institute). All other statistical analyses were performed using SAS 9.4 (SAS Institute Inc., Cary, NC, U.S.). Statistical significance was defined as $\mathrm{p}<0.05$.

\section{Results}

The study cohort consisted of 24407 men diagnosed with mPCa from 2008-2016 (Table 1). More than half of patients $(55.9 \%)$ were aged $65-84$ years, non-Hispanic White $(64.9 \%)$, and married $(57.1 \%)$. The majority of the patients lived in the Pacific Coast (50.8\%) and East regions (35\%). Stage M1b disease was most frequent $(74.3 \%)$, followed by M1c (19.6\%) and M1a (6.2\%). Poverty level varied among the cohort, with the highest number of patients falling $10-15 \%$ below the federal poverty level (33.3\%).

Multivariable Poisson regression models of incidence trends are presented in Table 2. The increase in incidence trend was observed across several subgroups, including age, race/ethnicity, regions, and poverty levels ( $\mathrm{p}<0.05$ for all interactions). Comparing 2008-2009 to 2014-2016, patients 75-84 years of age showed a $24 \%$ increase in the mPCa incidence rate (IRR $1.24,95 \% \mathrm{Cl} 1.15-1.35, \mathrm{p}<0.001)$. Similarly, there was a $31 \%$ increase in incidence for patients living in counties $0-10 \%$ below federal poverty level (IRR 1.31, 95\% Cl 1.22-1.40, $p<0.001$ ). Patients living in counties $>10-15 \%$ and $>20 \%$ below poverty level also showed increases in $\mathrm{mPCa}$ incidence of $19 \%$ (IRR 1.19, 95\% Cl 1.18-1.454, $\mathrm{p}<0.001$ ) and $18 \%$ (IRR 1.18, 95\% Cl 1.06-1.31, $\mathrm{p}<0.001$ ), respectively.

The impact of interactions between time period and each variable on mortality rates was evaluated in separate survival models. Because none of these interactions were statistically significant $(p<0.05)$, interactions were removed and models were re-run with main effects only, adjusted for all demographic variables (Table 3).

Despite increased incidence rates, men diagnosed with mPCa from 2012-2014 had a lower two-year cancerspecific mortality (hazard ratio [HR] $0.93,95 \% \mathrm{Cl} 0.89$ $0.97, \mathrm{p}=0.002)$ and overall mortality (HR 0.95, 95\% Cl 0.90$1.00, p=0.033$ ) compared to those diagnosed in 2008-2009. Slight decreases in overall and cancer-specific mortality from 2008-2009 until 2010-2011 were not significant. 


\begin{tabular}{|c|c|}
\hline Variable & Total $(n=24$ 407) \\
\hline & n (\%) \\
\hline \multicolumn{2}{|l|}{ Age group } \\
\hline 45-54 years & $1513(6.2)$ \\
\hline $55-64$ years & $5615(23.0)$ \\
\hline $65-74$ years & $7236(29.6)$ \\
\hline $75-84$ years & $6426(26.3)$ \\
\hline $85+$ years & $3617(14.8)$ \\
\hline \multicolumn{2}{|l|}{ Marital status } \\
\hline Married & $13930(57.1)$ \\
\hline Unmarried & $8832(36.2)$ \\
\hline Unknown & $1645(6.7)$ \\
\hline \multicolumn{2}{|l|}{ Insurance status } \\
\hline Uninsured & $840(3.4)$ \\
\hline Insured & $22709(93.0)$ \\
\hline Insurance status unknown & 858 (3.5) \\
\hline \multicolumn{2}{|l|}{ Geographic region } \\
\hline Alaska, Pacific Coast & $12396(50.8)$ \\
\hline East & $8535(35.0)$ \\
\hline Northern Plains & $2385(9.8)$ \\
\hline Southwest & $1091(4.5)$ \\
\hline \multicolumn{2}{|l|}{ Race/ethnicity } \\
\hline Non-Hispanic White & $15845(64.9)$ \\
\hline Non-Hispanic Black & 4271 (17.5) \\
\hline Non-Hispanic American Indian/Alaska & $165(0.7)$ \\
\hline Non-Hispanic Asian or Pacific Islander & $1404(5.8)$ \\
\hline Hispanic (all races) & $2722(11.2)$ \\
\hline \multicolumn{2}{|l|}{ Poverty level } \\
\hline $0-10 \%$ & $5060(20.7)$ \\
\hline$>10-15 \%$ & 8136 (33.3) \\
\hline$>15-20 \%$ & $7583(31.1)$ \\
\hline$>20 \%$ & $3628(14.9)$ \\
\hline \multicolumn{2}{|l|}{ Stage } \\
\hline M1a & $1502(6.2)$ \\
\hline M1b & $18124(74.3)$ \\
\hline M1c & 4781 (19.6) \\
\hline
\end{tabular}

\section{Discussion}

Previous reports have shown that the incidence of mPCa increased after 2007, which may be partially attributed to the 2008 USPSTF recommendation against screening in those 75 and older. ${ }^{5}$ Advances in imaging and screening techniques in the past decade is another plausible explanation for this trend. However, newer guideline changes in 2012 recommending against routine screening for men of all ages further supports the argument that this trend is most likely related to reduced screening and/or access to care. This study explores whether this trend is similar among different demographic subgroups and the interaction with disease and overall survival.

We found that there was a significant increase in incidence among certain groups, most notably those who were non-
Hispanic White, those who were $0-10 \%$ below federal poverty level, and those 75-84 years old. We hypothesize that non-Hispanic Whites, men who lived in counties $0-10 \%$ below poverty level, i.e., the least impoverished group, and men over 65 , the age that Medicare begins, likely had better access to screening in the past and therefore were impacted the most during this time period.

Previous studies have demonstrated that lower socioeconomic status is associated with diagnoses of more aggressive cancers, such as prostate and breast, both of which have established screening methods. ${ }^{11,12}$ After the changes in USPSTF guidelines on prostate cancer screening, patients in the lowest income brackets were likely impacted the least. ${ }^{13}$

Previous studies also described discrepancies in prostate cancer screening use in patients of different races. Caucasian men had shorter prostate cancer screening intervals as compared to African American men. ${ }^{14}$ Likewise, there were more diagnoses of prostate cancer without prior history of screening in African American men as compared to in Caucasian men. ${ }^{15}$ Interestingly, after controlling for socioeconomic factors, the disparity in prostate cancer mortality from 1992-1999 between African Americans and Caucasians was reduced significantly. ${ }^{7}$ The recent trends in incidence of mPCa illustrated in our study further reinforces many of the conclusions drawn from the literature by highlighting certain demographic subgroups that benefited most from screening prior to the USPSTF guideline change.

Our results show that despite increases in mPCa incidence over time, the risk of prostate cancer-specific mortality decreased in later time intervals. Specifically, patients diagnosed from 2012-2014 showed a 7\% reduction in prostate cancer-specific mortality, while patients diagnosed from 2010-2011 only showed a 4\% reduction in prostate cancerspecific mortality when compared to those diagnosed from 2008-2009. These findings may reflect the recent advances in treatment for prostate cancer and/or improved access to care through the Patient Protection and Affordable Care Act, enacted in 2010. Studies using more granular data, including treatment information and insurance status, should be considered to examine these trends.

Certain subgroups demonstrated a lower risk of cancer-specific mortality, including those who were insured compared to uninsured and non-Hispanic Asian or Pacific Islander compared to non-Hispanic White. Not only is there an increased likelihood of advanced prostate cancer in uninsured patients compared to insured patients, but also insurance status acts as an important predictor for favorable treatment outcomes in patients with low-grade disease. ${ }^{13}$ The decreased risk of cancer-specific mortality in patients of non-Hispanic Asian or Pacific Islander background for multiple types of cancer (lung, colorectal, prostate, breast) is less well-described in the literature and warrants further investigation. ${ }^{16}$ 
Table 2. Adjusted metastatic prostate cancer incidence rates and incidence rate ratios by demographic subgroups, stage at diagnosis, and period with Bonferroni corrected CI, SEER 2008-2016

\begin{tabular}{|c|c|c|c|c|c|c|c|}
\hline & \multicolumn{4}{|c|}{ Estimated incidence rates (CI) per 100000} & \multicolumn{3}{|c|}{$\begin{array}{l}\text { Estimated incidence rate ratios (CI) per } 100000 \\
\text { (ref }=2008-2009)\end{array}$} \\
\hline & 2008-2009 & 2010-2011 & 2012-2013 & 2014-2016 & 2010-2011 & 2012-2013 & 2014-2016 \\
\hline Overall & $4.22(3.98-4.46)$ & $4.29(4.05-4.53)$ & $4.63(4.37-4.88)$ & $4.97(4.72-5.22)$ & $1.02(0.97-1.06)$ & $1.10(1.05-1.14)$ & $1.18(1.14-1.22)$ \\
\hline \multicolumn{8}{|l|}{ Age group } \\
\hline 45-54 years & $0.54(0.47-0.62)$ & $0.57(0.50-0.65)$ & $0.56(0.49-0.64)$ & $0.63(0.56-0.70)$ & $1.05(0.88-1.27)$ & $1.03(0.86-1.24)$ & $1.16(0.98-1.37)$ \\
\hline $55-64$ years & $2.54(2.33-2.75)$ & $2.49(2.28-2.69)$ & $2.69(2.48-2.90)$ & $2.87(2.68-3.06)$ & $0.98(0.89-1.08)$ & $1.06(0.96-1.17)$ & $1.13(1.04-1.23)$ \\
\hline $65-74$ years & $5.44(5.01-5.88)$ & $5.86(5.41-6.30)$ & $6.06(5.62-6.49)$ & $6.55(6.15-6.96)$ & $1.08(0.98-1.18)$ & $1.11(1.02-1.21)$ & $1.20(1.11-1.3)$ \\
\hline $75-84$ years & $\begin{array}{c}10.14 \\
(9.34-10.95)\end{array}$ & $\begin{array}{c}10.43 \\
(9.61-11.24)\end{array}$ & $\begin{array}{c}11.27 \\
(10.42-12.11)\end{array}$ & $\begin{array}{c}12.61 \\
(11.81-13.41)\end{array}$ & $1.03(0.94-1.13)$ & $1.11(1.02-1.21)$ & $1.24(1.15-1.35)$ \\
\hline $85+$ years & $\begin{array}{c}18.10 \\
(16.35-19.85)\end{array}$ & $\begin{array}{c}16.83 \\
(15.21-18.45)\end{array}$ & $\begin{array}{c}20.22 \\
(18.45-21.98)\end{array}$ & $\begin{array}{c}19.87 \\
(18.40-21.35)\end{array}$ & $0.93(0.82-1.05)$ & $1.12(1.00-1.25)$ & $1.10(0.99-1.22)$ \\
\hline \multicolumn{8}{|l|}{ Poverty level } \\
\hline $0-10 \%$ & $4.26(3.94-4.58)$ & $4.44(4.12-4.76)$ & $4.72(4.39-5.05)$ & $5.08(4.77-5.39)$ & $1.04(0.96-1.13)$ & $1.11(1.02-1.20)$ & $1.19(1.11-1.28)$ \\
\hline$>10-15 \%$ & $4.2(3.89-4.51)$ & $4.07(3.77-4.37)$ & $4.4(4.08-4.71)$ & $4.63(4.34-4.92)$ & $0.97(0.89-1.05)$ & $1.05(0.97-1.13)$ & $1.10(1.03-1.18)$ \\
\hline$>15-20 \%$ & $4.31(3.89-4.74)$ & $4.36(3.94-4.78)$ & $4.83(4.41-5.25)$ & $5.10(4.73-5.47)$ & $1.01(0.89-1.14)$ & $1.12(1-1.26)$ & $1.18(1.06-1.31)$ \\
\hline$>20 \%$ & $3.97(3.59-4.35)$ & $4.24(3.85-4.63)$ & $4.58(4.18-4.98)$ & $5.19(4.82-5.56)$ & $1.07(0.95-1.20)$ & 1.15 (1.03-1.29) & $1.31(1.18-1.45)$ \\
\hline \multicolumn{8}{|l|}{ Race/ethnicity } \\
\hline $\begin{array}{l}\text { Hispanic (all } \\
\text { races) }\end{array}$ & $4.21(3.76-4.66)$ & $4.14(3.71-4.56)$ & $4.45(4.03-4.87)$ & $4.21(3.89-4.53)$ & $0.98(0.85-1.13)$ & $1.06(0.92-1.21)$ & $1.00(0.88-1.13)$ \\
\hline $\begin{array}{l}\text { Non-Hispanic } \\
\text { American } \\
\text { Indian/Alaska }\end{array}$ & $4.42(2.56-6.29)$ & $4.11(2.38-5.84)$ & $5.09(3.24-6.94)$ & $5.02(3.60-6.45)$ & $0.93(0.51-1.69)$ & $1.15(0.66-2.01)$ & $1.14(0.68-1.89)$ \\
\hline $\begin{array}{l}\text { Non-Hispanic } \\
\text { Asian or Pacific } \\
\text { Islander }\end{array}$ & $2.78(2.38-3.17)$ & $2.20(1.86-2.53)$ & $2.6(2.25-2.95)$ & $2.79(2.51-3.07)$ & $0.79(0.65-0.97)$ & $0.94(0.77-1.13)$ & $1.00(0.85-1.19)$ \\
\hline $\begin{array}{l}\text { Non-Hispanic } \\
\text { Black }\end{array}$ & $\begin{array}{c}9.45 \\
(8.64-10.26)\end{array}$ & $\begin{array}{c}9.54 \\
(8.75-10.32)\end{array}$ & $\begin{array}{c}9.52 \\
(8.76-10.28)\end{array}$ & $\begin{array}{c}9.88 \\
(9.24-10.51)\end{array}$ & $1.01(0.90-1.13)$ & $1.01(0.90-1.12)$ & $1.05(0.95-1.15)$ \\
\hline $\begin{array}{l}\text { Non-Hispanic } \\
\text { White }\end{array}$ & $3.58(3.41-3.76)$ & $3.74(3.56-3.93)$ & $4.09(3.90-4.28)$ & $4.54(4.36-4.72)$ & $1.04(0.98-1.11)$ & $1.14(1.08-1.21)$ & $1.27(1.20-1.33)$ \\
\hline \multicolumn{8}{|l|}{ Region } \\
\hline East & $3.78(3.50-4.05)$ & $4.01(3.73-4.29)$ & $4.15(3.87-4.44)$ & $4.59(4.32-4.87)$ & $1.06(0.98-1.15)$ & $1.1(1.02-1.19)$ & $1.22(1.13-1.31)$ \\
\hline Northern Plains & $4.15(3.66-4.65)$ & $4.61(4.10-5.13)$ & $4.84(4.32-5.36)$ & $5.35(4.88-5.82)$ & $1.11(0.95-1.29)$ & $1.17(1.00-1.35)$ & $1.29(1.13-1.47)$ \\
\hline $\begin{array}{l}\text { Alaska, Pacific } \\
\text { Coast }\end{array}$ & $4.91(4.60-5.22)$ & $4.73(4.44-5.03)$ & $5.23(4.91-5.54)$ & $5.48(5.19-5.77)$ & $0.96(0.90-1.03)$ & $1.06(1.00-1.13)$ & $1.12(1.05-1.18)$ \\
\hline Southwest & $3.46(2.85-4.08)$ & $3.75(3.13-4.37)$ & $4.57(3.90-5.24)$ & $4.8(4.25-5.35)$ & $1.08(0.86-1.37)$ & $1.32(1.06-1.65)$ & $1.39(1.13-1.70)$ \\
\hline \multicolumn{8}{|l|}{ Stage } \\
\hline M1a & $1.04(0.88-1.20)$ & $1.13(0.96-1.29)$ & $1.24(1.08-1.41)$ & 1.68 (1.52-1.84) & $1.09(0.89-1.34)$ & $1.2(0.98-1.46)$ & $1.62(1.36-1.93)$ \\
\hline M1b & $\begin{array}{c}14.24 \\
(13.41-15.06)\end{array}$ & $\begin{array}{c}15.38 \\
(14.52-16.25)\end{array}$ & $\begin{array}{c}16.65 \\
(15.74-17.55)\end{array}$ & $\begin{array}{c}17.79 \\
(16.91-18.67)\end{array}$ & $1.08(1.02-1.14)$ & $1.17(1.11-1.23)$ & $1.25(1.19-1.31)$ \\
\hline M1c & $5.02(4.62-5.42)$ & $4.10(3.75-4.44)$ & $4.35(4.00-4.7)$ & $4.42(4.12-4.72)$ & $0.82(0.74-0.90)$ & $0.87(0.79-0.95)$ & $0.88(0.81-0.96)$ \\
\hline
\end{tabular}

SEER: Surveillance, Epidemiology, and End Results.

Conversely, we also found that certain subgroups demonstrated an increased risk of cancer-specific mortality, notably patients who were unmarried compared to married and who lived in counties $>20 \%$ below federal poverty level compared to $0-10 \%$ below poverty level. Unmarried men may lack the social support systems that are critical for cancer treatment and survival as compared to married men. Prior studies demonstrate marital status as a predictor of cancer mortality and prostate cancer-specific mortality. ${ }^{17}$ Using the SEER registry data, unmarried men had higher risk of pros- tate cancer-specific mortality compared to that of unmarried men between 1988 and 2003. ${ }^{18}$ Men living in areas below poverty level ( $>20 \%$ ) likely suffer from lack of access to cancer-related treatments and care, which may contribute to the significantly higher risk of both prostate cancer-specific and all-cause mortality. ${ }^{19}$ Although the results of our study show a direct association between percent below poverty level and increased risk of prostate cancer-specific mortality, only the $>20 \%$ below poverty level group is found to be statistically significant. 
SEER: Incidence \& mortality trends of metastatic PCa

Table 3. Multivariable Cox proportional hazards models for all-cause and prostate cancer-specific mortality in men with metastatic prostate cancer, SEER 2008-2014

\begin{tabular}{|c|c|c|c|c|}
\hline & \multicolumn{2}{|c|}{ All-cause mortality } & \multicolumn{2}{|c|}{ Prostate cancer mortality } \\
\hline & $\mathbf{H R}^{\dagger}$ & $\mathbf{p}$ & $\mathbf{H R}^{\dagger}$ & $\mathbf{p}$ \\
\hline \multicolumn{5}{|l|}{ Period (ref=2008-2009) } \\
\hline 2010-2011 & $0.97(0.92-1.02)$ & 0.2 & $0.96(0.92-1.01)$ & 0.09 \\
\hline 2012-2014 & $0.95(0.90-1.00)$ & 0.03 & $0.93(0.89-0.97)$ & 0.002 \\
\hline \multicolumn{5}{|l|}{ Age group (ref=20-54 years) } \\
\hline $55-64$ years & $0.93(0.85-1.01)$ & 0.08 & $0.99(0.91-1.07)$ & 0.7 \\
\hline $65-74$ years & $0.96(0.89-1.05)$ & 0.4 & $1.10(1.01-1.19)$ & 0.02 \\
\hline $75-84$ years & $1.27(1.16-1.38)$ & $<0.0001$ & $1.52(1.41-1.65)$ & $<0.0001$ \\
\hline $85+$ years & $1.80(1.64-1.97)$ & $<0.0001$ & $2.31(2.13-2.51)$ & $<0.0001$ \\
\hline \multicolumn{5}{|l|}{ Insurance status (ref=uninsured) } \\
\hline Insured & $0.85(0.77-0.95)$ & 0.003 & $0.88(0.80-0.97)$ & 0.01 \\
\hline Insurance status unknown & $0.88(0.76-1.02)$ & 0.1 & $0.91(0.80-1.04)$ & 0.2 \\
\hline \multicolumn{5}{|l|}{ Marital status (ref=married) } \\
\hline Unmarried & $1.20(1.15-1.26)$ & $<0.0001$ & $1.23(1.19-1.28)$ & $<0.0001$ \\
\hline Unknown & $0.98(0.90-1.06)$ & 0.6 & $0.99(0.92-1.06)$ & 0.7 \\
\hline \multicolumn{5}{|l|}{ Geographic region (ref=East) } \\
\hline Alaska, Pacific Coast & $1.04(0.99-1.09)$ & 0.1 & $1.01(0.97-1.05)$ & 0.8 \\
\hline Northern Plains & $0.99(0.92-1.06)$ & 0.7 & $1.00(0.94-1.06)$ & 0.9 \\
\hline Southwest & $0.97(0.87-1.07)$ & 0.5 & $0.94(0.86-1.03)$ & 0.2 \\
\hline \multicolumn{5}{|l|}{ Race/ethnicity (ref=White) } \\
\hline Non-Hispanic Black & $1.02(0.96-1.08)$ & 0.5 & $1.04(0.99-1.09)$ & 0.1 \\
\hline Non-Hispanic American Indian/Alaska Native & $1.04(0.81-1.32)$ & 0.8 & $1.04(0.84-1.28)$ & 0.7 \\
\hline Non-Hispanic Asian or Pacific Islander & $0.73(0.67-0.81)$ & $<0.0001$ & $0.77(0.71-0.84)$ & $<0.0001$ \\
\hline Hispanic (all races) & $0.94(0.88-1.01)$ & 0.07 & $0.95(0.89-1.00)$ & 0.06 \\
\hline \multicolumn{5}{|l|}{ Poverty level (ref=0-10\%) } \\
\hline$>10-15 \%$ & $1.01(0.96-1.07)$ & 0.7 & $1.00(0.95-1.05)$ & 1.0 \\
\hline$>15-20 \%$ & $1.04(0.98-1.11)$ & 0.2 & $1.04(0.99-1.09)$ & 0.17 \\
\hline$>20 \%$ & $1.09(1.02-1.17)$ & 0.01 & 1.10 (1.04-1.17) & 0.002 \\
\hline
\end{tabular}

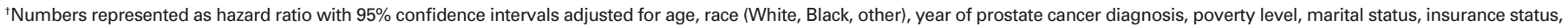
and geographic region of SEER registry. HR: hazard ratio; SEER: Surveillance, Epidemiology, and End Results.

Several limitations should be noted that are inherent in the SEER research data and were described previously. ${ }^{9}$ First, this study is not able to assess whether screening guidelines were implemented for individual cases and can only make inferences based on time periods. Second, factors such as access to health insurance may influence these trends and were not accounted for in the incidence rate analysis because this is not collected for the general population in the U.S. census data. Likewise, SEER data does not include important risk factors and clinical factors, such as smoking, alcohol intake, diet, family history, and comorbidities, which may impact incidence and survival analyses by acting as confounding variables. Finally, this study did not incorporate a time-series design because there were too few years (nine years) for this type of analysis.

It is possible that the increased rates by periods are consistent from 2008-2016 and do not represent a change in the existing trend. It is also possible that there may be lagged effects. For example, in some subgroups, rates for 2012-2013 were not markedly higher than 2010-2011 rates.
This could reflect the early adoption in the clinical community for restrictive screening guidelines before they were officially recommended in 2012. Nonetheless, the fact that only certain groups seem to be driving the increasing trend in $\mathrm{mPCa}$ incidence rates is worth noting. Furthermore, in order to ensure that all patients had at least two years of followup from diagnosis of $\mathrm{mPCa}$, the survival analysis was restricted to patients diagnosed between 2008 and 2014. This poses a limitation because the patients had unequal followup time and two-year followup time, rather than the more standard five-year follow up period, may not be adequate for assessing cancer-specific or overall mortality.

\section{Conclusions}

The overall incidence of mPCa increased from 2008 to 2016. We were able to show an increase in incidence of mPCa over time in patients living in the least impoverished areas and in non-Hispanic Whites, reflecting that the increase in diagnoses may be driven by demographic subgroups that benefited most 
from routine screening prior to the USPSTF recommendation against screening in 2012. We also demonstrated that despite decreased prostate cancer-specific mortality in recent years, perhaps due to the advances in treatment and access to care, certain demographic subgroups saw an increase in risk of prostate cancer-specific mortality. The differences in mortality risk were largely explained by these groups lacking access to resources and social support systems that are critical for favorable treatment outcomes. Future studies should examine the impact of more recent USPTSF guidelines for re-instituting screening and implementation of newer prostate cancer therapies in different subgroups.

Competing interests: The authors do not report any competing personal or financial interests related to this work.

This paper has been peer-reviewed.

\section{References}

1. Siegel RL, Miller KD, Jemal A. Cancer statistics, 2020. CA Cancer J Clin 2020;70:7-30. https://doi. org/10.3322/caac.21590

2. National Cancer Institute. Stat Facts: Prostate Cancer. Modified September 27, 2021. Available at: https://seer.cancer.gov/staffacts/html/prost.html. Accessed Aug. 1, 2020.

3. Moyer VA, Force USPST. Screening for prostate cancer: U.S. Preventive Services Task Force recommendation statement. Ann Intern Med 2012;157:120-34. https://doi.org/10.7326/0003-4819-157-2 201207170-00459

4. Hu JC, Nguyen P, Mao J, et al. Increase in prostate cancer distant metastases at diagnosis in the United States. JAMA Oncol 2017;3:705-7. https://doi.org/10.1001/jamaoncol.2016.5465

5. Weiner $A B$, Matulewicz RS, Eggener SE, et al. Increasing incidence of metastatic prostate cancer in the United States (2004-2013). Prostate Cancer Prostatic Dis 2016;19:395-7. https://doi.org/10.1038/ pcan. 2016.30

6. Jemal A, Ward EM, Johnson CJ, et al. Annual report to the nation on the status of cancer, 1975-2014, featuring survival. J Natl Cancer Inst 2017;109:djx030. ht1ps://doi.org/10.1093/inci/djx030

7. Du XL, Fang S, Coker AL, et al. Racial disparity and socioeconomic status in association with survival in older men with local/regional stage prostate carcinoma: Findings from a large community-based cohort. Cancer 2006;106:1276-85. https://doi.org/10.1002/cncr.21732
8. SEER Program (www.seer.cancer.gov) SEER*Stat Database: Incidence - SEER 18 Regs Research Data + Hurricane Katrina Impacted Louisiana Cases, Nov 2018 Sub (2000-2016) <Katrina/Rita Population Adjustment - Linked To County Attributes - Total U.S., 1969-2017 Counties, National Cancer Institute, DCCPS, Surveillance Research Program. Published April 2019, based on the November 2018 submission. Available at: hittps://seer.cancer.gov/data-software/documentation/seerstat/nov2018/. Accessed August 1, 2020.

9. Scosyrev E, Messing J, Noyes K, et al. Surveillance Epidemiology, and End Results (SEER) program and population-based research in urologic oncology: An overview. Urol Oncol 2012;30:126-32. https://doi.org/10.1016/j.urolonc.2009.11.005

10. National Cancer Institute. SEER Registrar Staging Assistant. Available at: https://staging.seer.cancer.gov/ tnm/input/1.9/prostate/clin_m/? breadcrumbs=( _schema_list ). Accessed Aug. 1, 2020.

11. Clegg $L X$, Reichman $M E$, Miller $B A$, et al. Impact of socioeconomic status on cancer incidence and stage at diagnosis: Selected findings from the surveillance, epidemiology, and end results: National longitudinal mortality study. Cancer Causes Control 2009;20:417-35. https://doi.org/10.1007/s10552-008-9256-0

12. Rundle A, Neckerman KM, Sheehan D, et al. A prospective study of socioeconomic status, prostate cancer screening and incidence among men at high risk for prostate cancer. Cancer Causes Control 2013;24:297303. hittps://doi.org/10.1007/s10552-012-0108-6

13. Clegg LX, Li FP, Hankey BF, et al. Cancer survival among US whites and minorities: A SEER (Surveillance, Epidemiology, and End Results) program population-based study. Arch Intern Med 2002;162:1985-93. hitps://doi.org/10.1001/archinte.162.17.1985

14. Carpenter WR, Howard DL, Taylor YJ, et al. Racial differences in PSA screening interval and stage at diagnosis. Cancer Causes Control 2010;21:1071-80. https://doi.org/10.1007/s10552-010-9535-4

15. Carpenter WR, Godley PA, Clark JA, et al. Racial differences in trust and regular source of patient care and the implications for prostate cancer screening use. Cancer 2009;115:5048-59. https://doi.org/10.1002/cncr.24539

16. Awasthi S, Gerke T, Williams VL, et al. Interrelationship between health insurance status and prostate cancer grade can have critical impact on prostate cancer disease control: A retrospective cohort study. Cancer Control 2019;26:1073274819837184. https://doi.org/10.1177/1073274819837184

17. Aizer AA, Chen MH, McCarthy EP, et al. Marital status and survival in patients with cancer. J Clin Oncol 2013;31:3869-76. https://doi.org/10.1200/JC0.2013.49.6489

18. Tyson MD, Andrews PE, Etzioni DA, et al. Marital status and prostate cancer outcomes. Can I Urol 2013;20:6702-6.

19. Cheng I, Witte IS, McClure LA, et al. Socioeconomic status and prostate cancer incidence and mortality rates among the diverse population of California. Cancer Causes Control 2009;20:1431-40. https://doi.org/10.1007/s10552-009-9369-0

Correspondence: Dr. Michael A. Feuerstein, Assistant Professor, Zucker School of Medicine at Hofstra/Northwell, Department of Urology, Lenox Hill Hospital, New York, NY, United States; mfeuerste1@northwell.edu 


\begin{tabular}{|c|c|c|c|c|}
\hline & \multicolumn{2}{|c|}{ All-cause mortality } & \multicolumn{2}{|c|}{ Prostate cancer mortality } \\
\hline & $\mathbf{H R}^{\dagger}$ & $\mathbf{p}$ & $\mathbf{H R}^{\dagger}$ & $\mathbf{p}$ \\
\hline \multicolumn{5}{|l|}{ Period (ref=2008-2009) } \\
\hline 2010-2011 & $0.96(0.92-1.01)$ & 0.1 & $0.97(0.92-1.02)$ & 0.2 \\
\hline 2012-2014 & $0.94(0.90-0.98)$ & 0.006 & $0.95(0.91-1.00)$ & 0.06 \\
\hline \multicolumn{5}{|l|}{ Age group (ref=20-54 years) } \\
\hline $55-64$ years & $0.99(0.92-1.08)$ & 0.9 & $0.94(0.86-1.02)$ & 0.1 \\
\hline $65-74$ years & $1.09(1.01-1.19)$ & 0.03 & $0.97(0.89-1.06)$ & 0.5 \\
\hline $75-84$ years & $1.51(1.39-1.64)$ & $<0.0001$ & $1.27(1.16-1.39)$ & $<0.0001$ \\
\hline $85+$ years & $2.29(2.11-2.49)$ & $<0.0001$ & $1.81(1.65-1.99)$ & $<0.0001$ \\
\hline \multicolumn{5}{|l|}{ Insurance status (ref=uninsured) } \\
\hline Insured & $0.91(0.83-1.00)$ & 0.06 & $0.88(0.79-0.98)$ & 0.02 \\
\hline Insurance status unknown & $0.93(0.81-1.06)$ & 0.3 & $0.90(0.79-1.05)$ & 0.2 \\
\hline \multicolumn{5}{|l|}{ Marital status (ref=married) } \\
\hline Unmarried & $1.22(1.18-1.27)$ & $<0.0001$ & $1.20(1.15-1.25)$ & $<0.0001$ \\
\hline Unknown & $0.98(0.91-1.05)$ & 0.5 & $0.97(0.89-1.06)$ & 0.5 \\
\hline \multicolumn{5}{|l|}{ Geographic region (ref=East) } \\
\hline Alaska, Pacific Coast & $1.00(0.96-1.04)$ & 0.9 & $1.03(0.98-1.08)$ & 0.2 \\
\hline Northern Plains & $0.99(0.93-1.05)$ & 0.8 & $0.98(0.91-1.05)$ & 0.6 \\
\hline Southwest & $0.93(0.85-1.02)$ & 0.1 & $0.96(0.86-1.06)$ & 0.4 \\
\hline \multicolumn{5}{|l|}{ Race/ethnicity (ref=White) } \\
\hline Non-Hispanic Black & $1.03(0.98-1.08)$ & 0.3 & $1.01(0.96-1.07)$ & 0.7 \\
\hline Non-Hispanic American Indian/Alaska Native & $1.03(0.83-1.27)$ & 0.8 & $1.04(0.81-1.32)$ & 0.8 \\
\hline Non-Hispanic Asian or Pacific Islander & $0.77(0.71-0.83)$ & $<0.0001$ & $0.73(0.66-0.80)$ & $<0.0001$ \\
\hline Hispanic (all races) & $0.94(0.89-1.00)$ & 0.05 & $0.94(0.88-1.00)$ & 0.07 \\
\hline \multicolumn{5}{|l|}{ Poverty level (ref=0-10\%) } \\
\hline$>10-15 \%$ & $1.01(0.96-1.06)$ & 0.8 & $1.02(0.96-1.08)$ & 0.5 \\
\hline$>15-20 \%$ & $1.03(0.98-1.09)$ & 0.2 & $1.04(0.98-1.10)$ & 0.2 \\
\hline$>20 \%$ & $1.11(1.04-1.18)$ & 0.001 & $1.10(1.02-1.18)$ & 0.01 \\
\hline
\end{tabular}

${ }^{\dagger}$ Numbers represented as hazard ratio with 95\% confidence intervals adjusted for age, race (White, Black, other), year of prostate cancer diagnosis, poverty level, marital status, insurance status, and geographic region of SEER registry. HR: hazard ratio; SEER: Surveillance, Epidemiology, and End Results. 